\title{
Hepatitis B prevention in Victoria, Australia - the potential to protect
}

S Williams (stephanie.williams@health.vic.gov.au) ${ }^{1,2,3}$, H Vally²,4, J Fielding ${ }^{1,3}$, B Cowie ${ }^{3,5}$

1. Communicable Disease Prevention and Control Unit, Department of Health, Victoria, Australia

2. National Centre for Epidemiology and Population Health, Australian National University, Canberra, Australia

3. Victorian Infectious Diseases Reference Laboratory, Melbourne, Australia

4. School of Public Health, La Trobe University, Melbourne, Australia

5. Victorian Infectious Diseases Service, The Royal Melbourne Hospital and Faculty of Medicine, Dentistry and Health Sciences, The University of Melbourne, Melbourne, Australia

Citation style for this article:

Williams S, Vally H, Fielding J, Cowie B. Hepatitis B prevention in Victoria, Australia - the potential to protect.

Euro Surveill. 2011;16(22):pii=19879. Available online: http://www.eurosurveillance.org/ViewArticle.aspx?Articleld=19879

Article published on 2 June 2011

People with chronic hepatitis $B(C H B)$ are a major source of incident hepatitis B virus (HBV) infection. The Department of Health in Victoria, Australia, recommends household contacts of CHB cases to be screened and funds hepatitis $B$ vaccination for those susceptible to infection. In July 2009, two cross-sectional surveys were conducted to assess the uptake of screening and vaccination: a postal survey of the treating doctors of a random sample of 65 CHB patients and a telephone survey of these patients. Twenty-six cases reported all adult household contacts had been screened, however only eight of these 26 patients reported that all susceptible adult contacts had been fully vaccinated. In contrast, child contacts of only three cases had been screened but 15 reported all child contacts to be fully vaccinated. Half of the surveyed doctors were unaware of state-funded hepatitis $B$ vaccine for contacts and only 10 had conducted any contact tracing. This study highlights the need for health departments to play a greater role in the management of CHB patients in order to support doctors' delivery of preventive services to people at high risk of HBV infection. These findings are relevant for all countries receiving immigrants from areas where hepatitis $B$ is endemic.

\section{Introduction}

Worldwide, about $2 \times 10^{9}$ people have been infected with the hepatitis B virus (HBV), and more than 350 million live with chronic hepatitis $B$ (CHB) virus infection [1]. Estimates of mortality attributable to $\mathrm{CHB}$ range from 600,000 to over 1 million deaths annually [1-3]. Australia is a low-prevalence country, with a hepatitis B surface antigen (HBsAg) prevalence of less than 2\% [4-6]. Over the last 20 years, however, the prevalence of CHB has increased, predominantly related to the increase in migration from highly endemic regions $[7,8]$. Currently there are an estimated 165,000 people with CHB infection in Australia, more than half of whom were born in other countries of the Asia-Pacific region [7-9]. About 55,000 of those infected are unaware of their diagnosis $[10,11]$. Predominant risk factors for
CHB in Australia are birth in a high prevalence country or being an Aboriginal or Torres Strait Islander [7].

In Australia, hepatitis B infections are reported as acute or unspecified (non-acute). Unspecified hepatitis $B$ (herein referred to as $\mathrm{CHB}$ ) requires detection of $\mathrm{HBsAg}$, or HBV by nucleic acid testing, in a patient with no prior evidence of HBV who does not meet criteria for acute infection [12.] In Victoria, from 1998 to 2008 , there were a total of 19,024 cases of confirmed CHB reported through the notifiable disease surveillance system, with between 1,497 and 1,938 cases annually [13]. Notification rates for CHB in the Melbourne metropolitan region were significantly higher than in nonmetropolitan regions of Victoria, reflecting findings of a recent serosurvey [14].

CHB is associated with significant morbidity and mortality. Approximately $25 \%$ of people with CHB develop advanced liver disease including cirrhosis and/or hepatocellular carcinoma (HCC) $[3,15]$. This excess mortality was demonstrated in a recent data linkage study in New South Wales, Australia that found that people living with CHB had standardised all-cause mortality 1.4 times higher than those without CHB [10]. In New South Wales, HCC incidence is rising faster than any other internal cancer $[16,17]$.

In Australia, universal hepatitis B vaccination for adolescents commenced in 1998 and for infants in 2000 , with the first of four doses given at birth [9]. In Victoria, in addition to the national immunisation programme, hepatitis $B$ vaccination is funded for healthcare workers, people who inject drugs, and household or sexual contacts of patients with $\mathrm{CHB}$ and people living with human immunodeficiency virus or acquired immunodeficiency syndrome (HIV/AIDS) [18]. Serologic testing before vaccination is recommended for families of CHB patients, as well as for members of families who have migrated from highprevalence countries [5]. 
Chronically infected individuals are a source of incident infections (in low and high prevalence countries alike) [19-22]. Furthermore, persons with undiagnosed $\mathrm{CHB}$ can remain asymptomatic for years and unaware of their risk for transmitting the virus to others or having liver disease in later life $[21,23]$. Therefore an adequate public health response to incident HBV infections must reduce opportunities for transmission from those chronically infected to those who are susceptible $[21,22]$.

Currently it is unknown whether or not tracing the household contacts of CHB patients takes place in accordance with Victorian recommendations, and the uptake of the funded hepatitis $B$ vaccine for contacts of $\mathrm{CHB}$ patients has not been evaluated. Consequently, the objectives of this study were firstly, to ascertain the uptake of screening and vaccination in household contacts of patients with $\mathrm{CHB}$, and secondly, to explore barriers to vaccination amongst household contacts of CHB cases.

\section{Methods}

\section{Study population}

Patients were randomly selected from the Notifiable Infectious Diseases Surveillance database maintained by the Victorian Department of Health. Patients were eligible for the study if they were notified to the department with CHB between 1 July 2008 and 31 December $2008(n=989)$. Our target sample size was 65 patients. Patients were excluded if no notifier details were recorded, or if no contact details for the cases were available after checking with the notifying doctor and/ or laboratory.

\section{Study design}

In Victoria, if a patient is randomly selected from the surveillance database as part of a study, it is customary that treating doctors are contacted first to ensure the patient is aware of their diagnosis prior to inviting their participation. We conducted two cross-sectional surveys to gather information from doctors and patients about patients and their household contacts.

The first survey was a postal survey sent to the doctors of 65 patients randomly selected from the 989 CHB patients. The second was a telephone survey of those patients whose treating doctor had given consent for the investigators to contact their patient. On calling patients, a confidentiality statement was read to each patient, verbal consent obtained and an appointment was made to interview them.

The doctor survey assessed knowledge of the Victorian recommendations regarding the hepatitis $B$ vaccine and attitudes about a doctor's role in contact tracing. It also assessed whether the doctors had attempted to trace household contacts of their patient in the sample, and if so, whether they documented the screening and vaccination status of their patients' household contacts.
The patient survey assessed the uptake of screening and vaccination of household contacts following the index patient's diagnosis. Interviews were conducted with an interpreter when necessary. The principal outcome was the proportion of patients whose susceptible household contacts had been fully vaccinated against hepatitis B. Patients were asked for each contact's age, screening history, and if susceptible to HBV, the number of doses of hepatitis $B$ vaccine received. Vaccination of contacts and serologic confirmation of immunity were reported by the patients and not otherwise verified, and reasons for non-vaccination were sought when applicable.

A secondary aim of the patient survey was to assess knowledge regarding hepatitis $B$ transmission by asking respondents to provide an example of how to prevent the spread of hepatitis $B$ infection. Patients were considered to have an understanding of preventing spread if they stated any one of the following methods: no sharing of certain household items such as razors, keeping wounds covered, practising safe sex, no donation of blood or organs, or vaccination of contacts.

\section{Data analysis}

Data were entered into Microsoft Access and analyses conducted using STATA v9. Household contacts' vaccination status was analysed according to each patient because household contact observations are not independent. If all adult and/or child contacts of a patient had been tested or vaccinated, this was considered a positive outcome. If a patient was uncertain about the status of any contact, all contacts of that patient were excluded from the analysis.

\section{Ethics}

Human research ethics approval was granted by The Australian National University (Study number 2009/552).

\section{Results}

The surveys were conducted in June and July 2009. Twenty-four doctors returned the surveys and two doctors were interviewed by telephone for a doctor response rate of 26 of 65 . We telephoned the 39 doctors who had not responded to the postal survey and obtained consent from 21 of them to call their patient. Therefore a total of 47 patients were eligible. Of these, four patients were unable to be contacted and doctors of five patients requested their patient not be contacted by the investigators. The remaining 38 patients all agreed to participate in the study.

\section{Doctor survey}

The majority of doctors who participated in the study were metropolitan general practitioners (GPs) $(23 / 26)$. Others included two hospital-based doctors and one rural GP. Of 39 non-responders, 37 were metropolitan GPs and the remaining two represented private blood screening services. As our sampling frame was CHB patients, doctors that did and did not participate in our study reflect 
that CHB notifications are concentrated in metropolitan regions and largely managed in primary care settings.

Thirteen of 26 doctors were aware that hepatitis B vaccine for household contacts of CHB cases was funded by the Victorian Department of Health. All doctors agreed that general practitioners have a role in contact tracing for hepatitis $B$, however only 10 indicated that they had attempted contact tracing for their patient. Nine doctors suggested reasons for non-uptake of vaccination in household contacts: language and cultural barriers $(n=3)$, the perceived impact of having hepatitis $B$ on Australian residency applications $(n=2)$, and difficulty systematically following up contacts $(n=4)$.

\section{Patient survey}

The study population consisted of 47 patients of which 24 were male and 23 were female. The median age at notification for all patients was 34 years (interquartile range (IQR) 27-44 years).(Table 1). Forty-four patients lived in metropolitan Melbourne. Seven patients were interviewed with an interpreter.

\section{TABLE 1}

Patient demographics, hepatitis B patients, Victoria,

1 July-31 December $2008(n=47)$

\begin{tabular}{|c|c|c|c|}
\hline & & Number & Percentage \\
\hline \multicolumn{4}{|l|}{ Sex } \\
\hline & Male & 24 & $51 \%$ \\
\hline & Female & 23 & $49 \%$ \\
\hline & Total & 47 & $100 \%$ \\
\hline \multicolumn{4}{|l|}{ Age (years) } \\
\hline & $10-17$ & 1 & $2 \%$ \\
\hline & $18-29$ & 16 & $34 \%$ \\
\hline & $30-49$ & 22 & $47 \%$ \\
\hline & $50-69$ & 6 & $13 \%$ \\
\hline & $70-89$ & 2 & $4 \%$ \\
\hline & Total & 47 & $100 \%$ \\
\hline \multicolumn{4}{|c|}{ Region of residence } \\
\hline & Metropolitan & 44 & $94 \%$ \\
\hline & Rural & 3 & $6 \%$ \\
\hline & Total & 47 & $100 \%$ \\
\hline \multicolumn{4}{|c|}{ Country of birth } \\
\hline & Australia & 3 & $6 \%$ \\
\hline & Overseas & 44 & $94 \%$ \\
\hline & Total & 47 & $100 \%$ \\
\hline \multicolumn{4}{|c|}{ Years of arrival ${ }^{a}$} \\
\hline & $1950-1959$ & 2 & $5 \%$ \\
\hline & $1960-1969$ & 1 & $3 \%$ \\
\hline & $1980-1989$ & 4 & $10 \%$ \\
\hline & 1990-1999 & 6 & $15 \%$ \\
\hline & $2000-2008$ & 26 & $67 \%$ \\
\hline & Total & 39 & $100 \%$ \\
\hline
\end{tabular}

${ }^{a}$ For whom this information as known.
Forty-four patients were born overseas. Approximately half of them were born in Vietnam $(n=12)$ and China $(n=11)$ (Table 2). Information on the year of their arrival in Australia was available for 39 of these patients and ranged from 1958 to 2008 . More than two thirds of the 39 patients $(n=26)$ had arrived since 2000 . For patients born overseas, the median time between arrival in Australia and notification with CHB was five years (IQR 1-17 years).

Of 38 patients interviewed, 18 had been aware of their hepatitis $B$ infection up to several years prior to notification in 2008. Eleven of these 18 patients had been tested in their country of birth prior to arrival in Australia. For patients diagnosed in their country of birth, the median time between first diagnosis and notification in Australia was 8.5 years (IQR 2.5-11 years).

Of the 32 patients who answered the question about transmission of hepatitis $B$, the most common responses were avoiding unprotected sex $(n=8)$ or avoiding blood donation $(n=7)$. Thirteen patients were unable to give an example of how to prevent the spread of the virus. Two patients said that not sharing cups and spoons prevented the spread and one patient believed the virus was transmitted by food. Only one patient suggested vaccination of family members prevented the transmission of the virus.

\section{Household contact vaccination results}

Household contact information was available for 41 patients. Patients commonly had one adult household contact $(n=19)$ and no contacts under the age of 18

\section{TABLE 2}

Countries of birth, hepatitis B patients, Victoria,

1 July-31 December $2008(n=44)$

\begin{tabular}{|l|c|c|}
\hline Countries of birth & Number & Percentage \\
\hline Vietnam & 12 & $27 \%$ \\
\hline China & 11 & $25 \%$ \\
\hline New Zealand & 3 & $7 \%$ \\
\hline Burma & 3 & $7 \%$ \\
\hline Sudan & 2 & $5 \%$ \\
\hline Cambodia & 2 & $5 \%$ \\
\hline Thailand & 2 & $5 \%$ \\
\hline Afghanistan & 1 & $2 \%$ \\
\hline India & 1 & $2 \%$ \\
\hline Greece & 1 & $2 \%$ \\
\hline Romania & 1 & $2 \%$ \\
\hline Italy & 1 & $2 \%$ \\
\hline Liberia & 1 & $2 \%$ \\
\hline Bangladesh & 1 & $2 \%$ \\
\hline Kuwait & 1 & $2 \%$ \\
\hline Netherlands & 44 & $2 \%$ \\
\hline Total & & $100 \%$ \\
\hline
\end{tabular}


$(n=17)$. For 37 of these 41 patients, household contacts included family members only.

Twenty-six patients reported that all adult household contacts had been tested for hepatitis B. Testing histories of all child contacts were available for 21 patients and of these, only three cases reported all eligible child contacts had been tested (Table 3 ). Children were considered eligible for testing if they were older than 18 months of age.

Information about vaccination of all eligible adult contacts was available for 26 patients, and of all eligible child contacts, for 20 patients. Eligible adult contacts of 8 (31\%, 95\% confidence interval (Cl): 12-50\%) of 26 patients were reported to be fully vaccinated against hepatitis B. In contrast, the majority of patients with eligible child contacts ( $75 \%, 95 \% \mathrm{Cl}: 54-96 \%)$ reported that all had been fully vaccinated (Table 3 ). Child vaccination had occurred as part of the national immunisation programme in 11 patients, whereas the child contacts of four patients had been vaccinated as part of contact tracing despite being eligible for participation in the national immunisation programme (Table 3 ).

Barriers to screening and vaccination of contacts Patients were asked for the reasons why any of their contacts were not vaccinated. Of 38 eligible adult

\section{TABLE 3}

Testing and vaccination data of household contacts of hepatitis B patients, Victoria, 1 July-31 December 2008 $(\mathrm{n}=41$ patients)

\begin{tabular}{|c|c|c|c|}
\hline & Number & Percentage & $95 \% \mathrm{Cl}$ \\
\hline \multicolumn{4}{|c|}{ Patients for whom all adult contacts were screened } \\
\hline Yes & 26 & $68 \%$ & $53-84 \%$ \\
\hline No & 12 & $32 \%$ & $16-47 \%$ \\
\hline Total & 38 & $100 \%$ & \\
\hline \multicolumn{4}{|c|}{ Patients for whom all eligible child contacts were screened } \\
\hline Yes & 3 & $14 \%$ & $0-31 \%$ \\
\hline No & 18 & $86 \%$ & $69-100 \%$ \\
\hline Total & 21 & $100 \%$ & \\
\hline \multicolumn{4}{|c|}{ Patients whose adult contacts were all fully vaccinated } \\
\hline Yes & 8 & $31 \%$ & $12-50 \%$ \\
\hline No & 18 & $69 \%$ & $50-88 \%$ \\
\hline Total & 26 & $100 \%$ & \\
\hline \multicolumn{4}{|c|}{ Patients whose child contacts were all fully vaccinated } \\
\hline Yes & 15 & $75 \%$ & $54-96 \%$ \\
\hline No & 5 & $25 \%$ & $4-46 \%$ \\
\hline Total & 20 & $100 \%$ & \\
\hline \multicolumn{4}{|c|}{ Reason why children were vaccinated } \\
\hline $\begin{array}{l}\text { National immunisation } \\
\text { programme }\end{array}$ & 16 & $80 \%$ & $61-99 \%$ \\
\hline Contact tracing & 4 & $20 \%$ & $1-39 \%$ \\
\hline Total & 20 & $100 \%$ & \\
\hline
\end{tabular}

contacts, responses were provided for 34 contacts of 22 patients. Most commonly, the patient reporting on the contact did not know the reason for non-vaccination $(n=19)$ and least commonly the contact had refused vaccine $(n=2)$. Four contacts were reported to be planning to start vaccination and 'other' reasons were stated for nine contacts. Only five patients expanded on 'other' reasons, which were fear of testing for hepatitis $B$, being unaware of the need for vaccination, living overseas, awaiting blood test results, and difficulty attending the GP.

\section{Discussion}

Our study showed that, despite recommendations for contact tracing and funded hepatitis B vaccine, the adult household contacts of less than a third of CHB patients had been vaccinated against hepatitis $B$. In contrast, the child household contacts of $75 \%$ of patients were reported to be fully vaccinated, mostly attributable to universal vaccination. We found it concerning that only half of the surveyed doctors were aware that hepatitis B vaccine was funded for household contacts. This is likely to be a key provider barrier to vaccination of household contacts [24]. All surveyed doctors felt that GPs have a role to play in contact tracing, however only $37 \%$ had conducted any contact tracing for their notified patient. We inferred that this was due to lack of knowledge of funded vaccination policy and to the difficulty of organising contact management, especially if contacts were not patients of the doctor's practice. Currently the Victorian Health Department relies on doctors to manage the contact tracing, however our small study suggests this assumption may need revisiting. Doctors' efforts to provide preventive services to populations at high risk for infection may benefit from public health collaboration [20].

Although 26 of 38 patients reported their contacts had been screened for hepatitis $B$, only a small number had been vaccinated. This suggests that being tested (and reported to be susceptible) is not necessarily sufficient to ensure participation in vaccination. It is worrying that only eight of 26 patients reported that all their adult contacts had been fully vaccinated, but it is consistent with published findings from other countries: In the United States, a study in San Diego found less than $20 \%$ of eligible contacts (including children) had been vaccinated, and in the United Kingdom (UK), a similar study found only $27 \%$ of contacts had been vaccinated $[20,25]$. A 10-year seroprevalence review of hepatitis $B$ in Italy also found $28 \%$ of new HBV cases were household contacts of CHB patients and had been unaware that free vaccine was available [26].

The limitations of this study included the small sample size of doctors and of patients that provided vaccination status of all of their contacts. In addition, obtaining a serological assessment of contacts' vaccination status would have strengthened the study, but this was not feasible. Previous studies have shown poor patient recall of their own vaccination status [27], therefore 
it is be reasonable to assume that recall of contacts' vaccination would also be poor. However, this may not have affected parents' recall of the vaccination history of their children as much as their recall of the status of other adult contacts. Uncertainty was partially managed at the analysis stage by excluding patients who were unsure of the vaccination status of one or more of their contacts.

Despite the study limitations, we feel that the findings build the argument for increasing public health collaboration in the management of chronic hepatitis $B$. It is a challenge for public health practitioners to increase participation in preventive programmes among high risk groups, who are often the most difficult to reach $[28,29]$. However for CHB in Australia, this relies on individual private doctors to implement public health policies. There is evidence that high participation $(>90 \%)$ of contacts in screening and vaccination can be achieved when integrated into current clinical models $[30,31]$. In Victoria, one intervention that could be introduced is direct communication of health information by mail or electronic mail between the health department and notified CHB patients. This aligns with the principles of the Ottawa Charter that communicating important health information is necessary to empower patients to manage their health [32], and could have the secondary benefit of improving the success of contact management [33]. Indeed, in a 2006 cohort study in the UK, receipt of written information about hepatitis $B$ was positively associated with infants born to HBsAg-positive mothers completing hepatitis $B$ vaccination [34].

This issue is not limited to Australia. In Europe there is geographical variation in the prevalence of HBV infection given the mixture of countries with medium and low HBsAg prevalence $[22,35]$. Furthermore, an increasing number of immigrants to Europe, often from highly endemic countries, is changing the hepatitis $B$ epidemiology in low endemic countries [35]. In 2009, a survey of 25 European Union Member States plus Norway and Iceland revealed that 20 had universal hepatitis B vaccination programmes in addition to targeting specific risk groups, while seven countries maintained hepatitis B vaccine for risk groups only [36]. Close family contacts of CHB cases were included in the risk groups in 18 of the 20 countries with routine immunisation and in all seven countries with selective immunisation programmes. Only 10 of 17 countries reported that vaccine was free to all people at increased risk by lifestyle, which included household contacts [36]. The experience in Australia suggests that the implementation of these targeted vaccination policies may need evaluation.

In conclusion, the findings from our study suggest that the vaccination of adult household contacts of CHB patients is inadequate. Although child contacts born in Australia were more likely to be fully immunised, this was largely due to the national immunisation programme. Our findings suggest that barriers to contact tracing include a lack of patient knowledge regarding CHB, limited awareness on the part of doctors of the funded vaccine, and limited capacity of individual doctors to organise systematic follow up of patients' contacts. Although more information is needed about the uptake of, and barriers to, screening and vaccination of contacts of patients with CHB in Victoria, we believe that information from this study should inform policy and programme considerations. There is evidence that active contact tracing for CHB patients can result in high participation rates in at-risk populations and that contact tracing is not always integrated into the core business of general practice. Improved communication from the health department directly to CHB patients, better targeted screening, and integrated contact tracing programmes will be vital to tackling the growing burden of complications from CHB in Australia. These findings are relevant to other countries with high net migration from areas with medium to high $\mathrm{HBsAg}$ prevalence.

\section{Acknowledgments}

This study was completed when Stephanie Williams was a Master of Applied Epidemiology scholar at the Australian National University, funded by the Australian Government Department of Health and Ageing.

\section{References}

1. World Health Organization (WHO). Hepatitis B. Fact Sheet No.204. Geneva: WHO; August 2008. Available from: http:// www.who.int/mediacentre/factsheets/fs204/en/index.html

2. Goldstein ST, Zhou F, Hadler SC, Bell BP, Mast EE, Margolis HS. A mathematical model to estimate global hepatitis $B$ disease burden and vaccination impact. Int J Epidemiol. 2005;34(6):1329-39.

3. Lavanchy D. Hepatitis B virus epidemiology, disease burden, treatment, and current and emerging prevention and control measures. J Viral Hepat. 2004;11(2):97-107.

4. Wood N, Backhouse J, Gidding HF, Gilbert GL, Lum G, McIntyre PB. Estimates of chronic hepatitis $B$ virus infection in the Northern Territory. Commun Dis Intell. 2005;29(3):289-90.

5. The Australian Immunisation Handbook. 9th ed. Canberra, Australia: Australian Government Department of Health and Ageing; 2008, updated 2009. Available from: http://www. health.gov.au/internet/immunise/publishing.nsf/Content/ Handbook-home.

6. Clements CJ, Baoping $\mathrm{Y}$, Crouch A, Hipgrave D, Mansoor O, Nelson CB, et al. Progress in the control of hepatitis B infection in the Western Pacific Region. Vaccine. 2006;24(12):1975-82.

7. O'Sullivan B, Gidding HF, Law M, Kaldor JM, Gilbert GL, Dore $\mathrm{GJ}$, et al. Estimates of chronic hepatitis $B$ virus infection in Australia, 2000. Aust N Z J Public Health. 2004;28(3):212-6.

8. Nguyen VT, Razali K, Amin J, Law MG, Dore GJ. Estimates and projections of hepatitis B-related hepatocellular carcinoma in Australia among people born in Asia-Pacific countries. J Gastroenterol Hepatol. 2008;23(6):922-9.

9. Gidding HF, Warlow M, MacIntyre CR, Backhouse J, Gilbert $\mathrm{GL}$, Quinn HE, et al. The impact of a new universal infant and school-based adolescent hepatitis $B$ vaccination program in Australia. Vaccine. 2007;25(51):8637-41.

10. Amin J, Law MG, Bartlett M, Kaldor JM, Dore GJ. Causes of death after diagnosis of hepatitis B or hepatitis C infection: a large community-based linkage study. Lancet. 2006;368(9539):938-45.

11. Cowie B, Kelly, H. Outcomes of a complex dynamic mathematical model of hepatitis B virus in Australia (PP 027). Proceedings of the 2oth Conference of the Asian Pacific Association for the Study of the Liver (APASL); 2010 Mar 26-28; Beijing, China. Hepatol Int. 2010;4(1):101. 
12. Australian national notifiable diseases and case definitions. Hepatitis B (unspecified) case definition. Canberra, Australia: Australian Government Department of Health and Ageing; Mar 2004. Available from: http://www.health.gov.au/internet/ main/publishing.nsf/Content/cda-surveil-nndss-casedefscd_hepbun.htm

13. Williams S, Vally H, Fielding J, Cowie B. Chronic hepatitis B surveillance in Victoria, 1998-2008: instituting a 21st century approach to an old disease. Aust N Z J Public Health. 2011;35(1):16-21.

14. Cowie B, Karapanagiotidis T, Enriquez A, Kelly, H. Markers of hepatitis $B$ virus infection and immunity in Victoria, Australia, 1995 to 2005. Aust N Z J Public Health. 2010;34(1):72-8

15. Yuen MF. Revisiting the natural history of chronic hepatitis B: impact of new concepts on clinical management. Gastroenterol Hepatol. 2007;22(7):973-6.

16. Robotin MC, George J, Supramaniam R, Sitas F, Penman AG. Preventing primary liver cancer: how well are we faring towards a national hepatitis B strategy? Med J Aust. 2008;188(6):363-5.

17. Coates M, Tracey E. Cancer in New South Wales: Incidence and mortality 1997. N S W Public Health Bull. 2001;12(2):40-2.

18. Immunisation Section. Criteria for government funded vaccine. Fact Sheet. Victoria, Australia: Victorian Government Department of Health; Nov 2010. Available from: http:// www.health.vic.gov.au/_data/assets/pdf_file/o018/414171/ Criteria-government-vaccine-Nov.10.pdf.

19. Hutton DW, Tan D, So SK, Brandeau ML. Cost-effectiveness of screening and vaccinating Asian and Pacific Islander adults for hepatitis B. Ann Intern Med. 2007;147(7):460-9.

20. Weinberg MS, Gunn RA, Mast EE, Gresham L, Ginsberg M. Preventing transmission of hepatitis $B$ virus from people with chronic infection. Am J Prev Med. 2001;20(4):272-6.

21. Weinbaum C, Williams I, Mast E, Wang S, Finelli L, Wasley A, et al. Recommendations for Identification and Public Health Management of persons with chronic hepatitis B. MMWR Recomm Rep. 2008;57(RR-8):1-20.

22. Rantala $M$, van de Laar MJ. Surveillance and epidemiology of hepatitis B and C in Europe - a review. Euro Surveill. 2008;13(21). pii:18880. Available from: http://www. eurosurveillance.org/ViewArticle.aspx?Articleld =18880

23. Caruana SR, Kelly HA, De Silva SL, Chea L, Nuon S, Saykao $\mathrm{P}$, et al. Knowledge about hepatitis and previous exposure to hepatitis viruses in immigrants and refugees from the Mekong Region. Aust N Z J Public Health. 2005;29(1):64-8.

24. Mast EE, Margolis HS, Fiore AE, Brink EW, Goldstein ST, Wang $\mathrm{SA}$, et al. A comprehensive immunization strategy to eliminate transmission of hepatitis B virus infection in the United States: recommendations of the Advisory Committee on Immunization Practices (ACIP) part 1: immunization of infants, children, and adolescents. MMWR Recomm Rep. 2005;54(RR-16):1-31.

25. Richardson G, Evans M, Westmoreland D. Hepatitis B immunisation of household contacts: retrospective study of vaccine coverage. J Epidemiol Community Health. 2001;55(12):934-5.

26. Stroffolini T, Mele A, Tosti M, Gallo G, Balocchini E, Ragni P, et al. The impact of the hepatitis B mass immunisation campaign on the incidence and risk factors of acute hepatitis B in Italy. J Hepatol. 2000;33(6):980-5.

27. Tawk HM, Vickery K, Bisset L, Selby W, Cossart YE. The impact of hepatitis B vaccination in a Western country: recall of vaccination and serological status in Australian adults. Vaccine. 2006;24(8):1095-106.

28. Kretzschmar M, Mangen MJ, van de Laar M, de Wit A. Mode based analysis of hepatitis $B$ vaccination strategies in the Netherlands. Vaccine. 2009;27(8):1254-60.

29. van Houdt R, Koedijk FD, Bruisten SM, Coul EL, Heijnen $M L$, Waldhober Q, et al. Hepatitis B vaccination targeted at behavioural risk groups in the Netherlands: does it work? Vaccine. 2009;27(27):3530-5.

30. Williams SJ, Craig PI, Liddle C, Batey RG, Farrell GC. Hepatitis B in Australia: determinants of intrafamily spread. Aust N Z J Med. 1987;17(2):220-7.

31. van Steenbergen JE, Baayen D, Peerbooms PG, Coutinho RA, van den Hoek A. Much gained by integrating contact tracing and vaccination in the hepatitis $B$ antenatal screening program in Amsterdam, 1992-1999. J Hepatol. 2004;40(6):979-85.

32. World Health Organization (WHO). Ottawa Charter for Health Promotion. First International Conference on Health Promotion: The move towards a new public health, Ottawa, Ontario, Canada. 17-21 Nov 1986. Geneva:WHO. Available from: http:// www.who.int/hpr/NPH/docs/ottawa_charter_hp.pdf

33. Hahné S, Wörmann Nee Marschall T, Kretzschmar M. Migrants and hepatitis B: new strategies for secondary prevention needed. Eur J Public Health. 2009;19(4):439.
34. Giraudon I, Permalloo N, Nixon G, Charlett A, Cohuet S, Mandal $S$, et al. Factors associated with incomplete vaccination of babies at risk of perinatal hepatitis $B$ transmission: a London study in 2006. Vaccine. 2009;27(14):2016-22.

35. Veldhuijzen I, Toy M, Hahné S, De Wit G, Schalm S, de Man RA, et al. Screening and early treatment of migrants for chronic hepatitis B virus infection is cost-effective. Gastroenterology. 2010;138(2):522-30.

36. Mereckiene J, Cotter S, Lopalco P, D’Ancona F, Levy-Bruhl D, Giambi C, et al. Hepatitis B immunisation programmes in European Union, Norway and Iceland: where we were in 2009? Vaccine. 2010;28(28):4470-7. 